\title{
Improvement of Conversation Skills through Script Fading in a Child with Autism Spectrum Disorder
}

\author{
Daniel Carvalho de Matos ${ }^{1,2}$ (1) , Pollianna Galvão Soares de Matos ${ }^{1,2}$ (), \\ Ana Flávia Lima Teles da Hora1 ${ }^{\circledR}$, Melina Serra Pereira1, Kaline Silva Azevedo ${ }^{1}$ \\ ${ }^{1}$ Department of Psychology, Ceuma University, São Luís, Brazil \\ ${ }^{2}$ Postgraduate Program in Psychology of the Federal University of Maranhão, São Luís, Brazil \\ Email: dcmatos23@hotmail.com
}

How to cite this paper: de Matos, D. C., de Matos, P. G. S., da Hora, A. F. L. T., Pereira, M. S., \& Azevedo, K. S. (2019). Improvement of Conversation Skills through Script Fading in a Child with Autism Spectrum Disorder. Creative Education, 10, 485-504. https://doi.org/10.4236/ce.2019.103035

Received: December 19, 2018

Accepted: March 1, 2019

Published: March 4, 2019

Copyright $\odot 2019$ by author(s) and Scientific Research Publishing Inc. This work is licensed under the Creative Commons Attribution International License (CC BY 4.0).

http://creativecommons.org/licenses/by/4.0/

\begin{abstract}
The script fading procedure aims to develop better communication skills of children and youngsters with Autism Spectrum Disorder in relationship with other people. The procedure seeks to incorporate cues in several contexts. Scripts may be organized in day-to-day situations of life, such as playful interactions among children and the scripts may consist in pictorial, textual or auditory stimuli. If a learner, for example, lacks conversation skills, but has good repertoire regarding textual behavior, scripts consisting of written phrases may be presented and the learner has to read them. The listener may interact with the speaker like he is emitting responses free from the control of scripts. With repetitive exposure to the contingency and the establishment of a more fluent repertoire of textual behavior, the script is gradually faded out by word removal one by one. This process continues until the learner's responses become free from the control of the whole scripts. Previous research has demonstrated the establishment of independent performance, maintenance and generalization to different settings and listeners. The purpose of this study was to assess the efficacy of this procedure in establishing conversation skills in a child aged 9 with ASD. Textual scripts were applied to three sets of conversation. After a baseline condition, training started and the experimental control by the independent variable was established through a multiple baseline design across the three different conversation topics. Independent performance was successfully established through reinforcement of correct performance and error correction. Although the interventions were conducted in a university-based laboratory, the established repertoires generalized to the child's school classroom and another listeners (another adult and a child). Implications to school inclusion regarding the establishment of con-
\end{abstract}


versation among children in school setting were discussed.

\section{Keywords}

Script Fading, Textual Behavior, Multiple Baseline,

Autism Spectrum Disorder

\section{Introduction}

\subsection{Objectives of the Study}

The Autism Spectrum Disorder (ASD) is considered a neurodevelopmental disorder (APA, 2013). In Psychology there are different conceptions on ASD. Applied behavior analysts, for example, developed interventions with the purpose of ameliorating learning impairments and behavior problems in individuals with autism (Richman, 2001). Even though some children have already shown skills related to language and communication to some extent, the scientific literature emphasizes that, for many learners, these skills are hardly ever demonstrated with the goal of initiating and maintaining a verbal interaction among other people and that the learners frequently lack spontaneity. This chapter had two goals: 1) to describe methodological aspects of some research on script fading and effects on the establishment of communication skills in children diagnosed with ASD; 2) to present a research report on the effects of script fading in a Brazilian child with ASD aged 9 years old.

\subsection{Behavior Analysis: Definitions and Treatment Approaches to ASD}

The Behavior Analysis approach emphasizes that human behaviors are greatly determined by their effects on environment (consequences) (Skinner, 2003). They are the product of interactions between the individuals and their environments and refer to contingency relations among environmental variables (the consequence and the context in which the individual responds) and behavioral variables. As an example, consider the case of a person who kicks a soccer ball to the goal. Depending on the effect on the kick, the manner with which it happens tends to recur in the future, considering that the consequence (goal/score) is said to be relevant for the person. This kind of relation is termed operant behavior.

Among learned operant behaviors, there are also cases related to language and communication (Skinner, 2003; Skinner, 1978). They are verbal behaviors, which are shaped and maintained by mediated consequences. The one who emits verbal behavior is called speaker and someone called listener provides a reinforcing consequence, responsible for the shaping and maintenance of the speaker's behavior. As an example, consider the case in which a child, with an adult in the same environment, presents an action figure of Spiderman and says enthusiastically "Spiderman!!”. The adult then says: “That is correct! And he has 
the power of throwing webs!". In this case, the child emits a kind of verbal operant behavior called tact and it is a repertoire extremely explored in intervention manuals in ABA concerned with the teaching of important skills to children with developmental disabilities (Greer \& Ross, 2008; Matos, 2016; Sundberg \& Partington, 1998). It is important to mention that, about the presented example regarding language, it is highlighted a verbal function, which, in the way it was demonstrated, represents spontaneous language because the verbal interaction was initiated by the child. Nevertheless, many learners with autism usually lackspontaneity and they frequently depend on prompts to respond (Carr, LeBlanc, Rosati, \& Conroy, 2012; Pérez-González, Pastor, \& Carnerero, 2014; Williams, Carnerero, \& Pérez-González, 2006).

The programmed teaching for learners with autism and other cases of learning disabilities in $\mathrm{ABA}$, regarding skills that also include conversation, may be conducted under different formats. Generically, these formats are termed: 1) discrete trial teaching (DTT) and 2) incidental teaching (IT). DTT comprises the planning and implementation of the teaching of skills in sequences of steps, similar to the shaping procedure previously implemented in basic research regarding learning processes in Behavior Analysis (Skinner, 2003). An example of discrete trial may consist in a task in which an adult manipulates objects in front of a child, so that he/she has the opportunity to learn to emit verbalizations of their names. Suppose that a group with four stimuli (e.g. pictures of apple, car, ball and soap) was selected for the activity, which consists in 12 teaching trials. The nonverbal stimuli (pictures) are randomized and each of them is presented in three of the 12 trials along a block of trials, so the number of opportunities with each picture is the same. In each trial, the learner has from 3 to $5 \mathrm{~s}$ to state the name of the picture upon its presentation and the presentation of a verbal stimulus such as "what is it?". If the learner's response is correct, the adult provides feedback, by saying, for example, "that is correct!".

On the other hand, considering that a social consequence may be insufficient in maintaining the verbal behavior being shaped, the adult may also manipulate high valued arbitrary reinforcers to strengthen the learner's correct performance. The teaching through discrete trial teaching is usually organized in a structured environment with the minimal of unwanted stimuli, which may compromise the learner's attention. It is also important to emphasize that the literature regarding this format of intervention sustains that it is effective indeed, but there are critics in the sense that, many times, the stimuli used in the learning settings are not functionally related to the responses, which are being taught. An example, which illustrates that, may be the effort to increase the likelihood that a learner will verbalize the word "car" in the presence of a toy car, but, as a reinforcing consequence, the adult delivers a candy, which was previously established as an extremely powerful reinforcer for a given child (Allen \& Cowan, 2008).

A certain mediation proposal establishes that the incidental teaching approach (IT) and variations involve the goal of manipulating reinforcers functionally related to the responses, which the teacher intends to shape in a child's repertoire. 
Different from the other case, the learning stimuli are selected through the most immediate learner's interests, instead of having the adult arbitrarily selecting the materials to be used in the teaching process. There is also a strong emphasis on spontaneity, considering that the learner should initiate the interactions. In a given research on incidental teaching with 4 and 5 years old children, it was programmed the teaching of verbal descriptions about their preferred reinforcing stimuli in natural environment as a condition for access to them (Rogers-Warren \& Warren, 1980). Incidental teaching is defined by several characteristics, such as: 1) it demands the elaboration of responses in children with language delays; 2 ) the preferred materials should be organized in a strategic way in the environment, so that they remain visible for the learners, but out of their reach; 3 ) it demands that a given learner emits a more complex verbalization, by organizing sentences or phrases in order to access preferred reinforcing stimuli; 4) the frequency with which the training is conducted should be a function of the number of times that the learner emits initiating responses; 5) if the learner shows interest for a given item, but does not emit a verbalization, the adult should wait some seconds and, if really necessary, a prompt may be shown to the learner, as a question. Procedures such as these may be relevant to promote generalization of learned skills (Allen \& Cowan, 2008).

As it was stated before, there are variations of procedures to teach incidental teaching, which were developed along the years. Among them, the following may be listed: 1) mand-model (Rogers-Warren \& Warren, 1980); time delay (Halle, Marshall, \& Spradlin, 1979); interruption of behavior chains to develop language (Alwell, Hunt, Goetz, \& Sailor, 1989); natural language paradigm and pivotal response training (Reagon \& Higbee, 2009); script fading (Krantz \& McClannahan, 1993). Since the emphasis of this study was on the script fading procedure, the following paragraphs present some methodological aspects of researches on this theme with the purpose of improving communication skills in children diagnosed with autism.

\subsection{Literature Review on Script Fading}

In the first study on script fading (Krantz \& McClannahan, 1993), the effects of using scripts consisting in sentences and their gradual fading were measured over the communication initiated by four children with autism during group activities at their school. In baseline, the children engaged in three activities (drawing, coloring and painting). Each received a piece of paper with the instructions "do your art" and "play a lot". If necessary, they were prompted to read the instructions. During the intervention with scripts, the activities were presented along with the instructions, as well as scripts with ten statements and questions related to present, past and future (e.g. "did you like to play in the swing yesterday?"). Three versions were organized for each child and, when necessary, an experimenter provided prompts to observe the materials. The main dependent variable (VD) of the research consisted in verbalizations or questions independent from the scripts and that should be directed to their same age peers 
in a classroom.

The fading of scripts was conducted in five phases and in a graduated manner to develop autonomy from the scripts. With the end of intervention, follow up sessions were conducted two months later. The script fading was successful for all participants; correct performance was maintained during follow up; and there was generalization to contexts different from those where the procedures were conducted (a wider classroom with new activities and a different adult present). The performances were similar to those by three typically developing children. It is important to emphasize that the increase of verbal interactions free from script control, after fading, also involved new and spontaneous responses, consisting in re-combinations of elements of the scripts with other existing verbal repertoires of the children.

Another research on script fading had the goal of extending the results from the previous one with three boys from 4 to 5 years old with a more limited reading repertoire (Krantz \& McClannahan, 1998). Verbal responses initiated by them were rare and were limited to the emission of one-word utterances to get access to preferred foods and toys. Data collection occurred in a classroom equipped with table, chairs and cabinets, which showed toys and school related materials. A known teacher was the person with whom the children could maintain interaction and she remained seated at one of the classroom corners. On the table there was a photographic activities schedule, consisting in 16 pictures (one for each page), which represented activities with toys to be performed by each child. Sessions comprised the manipulation of four different sequences of pictures and they were conducted once or twice a day. All children previously developed repertoires with activities schedules, so that, for each step with a picture, they should: 1) point to the picture depicting an activity; 2) get the materials related to the activity; 3 ) finish it and; 4) return the materials to their original place. In parallel, the children also learned to read the words "look" and "watch me" to evoke the teacher's attention to them.

The VDs of the research were the following: 1) spontaneous verbal interaction; 2) verbal interaction based on script; 3) elaborations as verbal responses different from the scripts. A multiple baseline design across different participants was employed to ensure experimental control. During baseline, the children were prompted physically to develop the photographic activities and it was terminated after three sessions without the use of prompts. During intervention, the difference was the presence of cards with the words "look" and "watch me" placed above or below a picture. Prompts for observing responses to the scripts were provided when necessary, as well as the dictated model of the names if the child was unable to read the word. After the verbalization, each child should perform the activity represented by the picture. Only one of the children needed adaptation by wearing a bracelet to signal him to say: "look" and "watch me" by the time he approached the teacher. After some sessions, the original procedure was reinstated. The criterion during the intervention consisted in reading the words without prompts in two consecutive sessions (Krantz \& McClannahan, 
1998).

The following condition involved the presence of another known teacher and the only difference was the fact that prompts were not presented. Later, the script fading commenced. It was programmed for ten from the 16 activities from the photographic activities schedule. The fading was conducted for all children at the same time in three steps (which involved the omission of part of a word or even the whole word). After criterion new activities were programmed and they were not related to the words used in training. Prompts, as well as scripts, were not provided. The results showed that the frequencies of elaboration responses and spontaneous interaction increased and they were maintained in the presence of a second teacher. There was maintenance of performance and generalization to new activities. The authors contend the hypothesis that the scripts represented important elements for conversation on the performed activities. The interactions, nevertheless, were always maintained among the children and adult relatives, but they did not generalize to other same age peers. The autistic children, however, demonstrated several new verbalizations, which could not be showed only from the used scripts. There is the hypothesis that the response feedbacks by the teachers improved the children's repertoire in the sense that they demonstrated new verbalizations beyond those depicted by the scripts and that this may be considered one important step for the development of a more fluent and natural language (Krantz \& McClannahan, 1998).

The effects of the fading of textual prompts were assessed on the conversation between two children with autism from 8 to 9 years old (Sarokoff, Taylor, \& Poulson, 2001). It was used a kind of product (e.g. a sweet), which had a textual prompt attached to it, that is, the own product's name. The hypothesis was that other supplemental textual stimuli could be manipulated and faded, so that the children could converse in the presence of the product and its name only. The sessions were conducted in the children's classroom. Two types of products were selected: snack and videogames. Each one remained on a piece of paper, which contained a textual script. The first word represented the product's name. The VDs consisted in verbalizations during sessions that lasted $3 \mathrm{~min}$ and were of two kinds: correspondent and non-correspondent to the scripts.

A multiple baseline design across three sets of products was used to ensure experimental control by script fading. During baseline, prompts and scripts were not used. The participants remained seated next to each other. A session was initiated when the experimenter presented the verbal instruction "eat a snack" or "play a videogame" along with the access to the items. During intervention, textual scripts were provided. There was access to each item when they read the script (e.g. "let's eat our snacks"). After reading the scripts correctly in two sessions, the fading was implemented in five steps. Both children demonstrated increase in the verbalizations based and not based on the scripts and with generalization to another environment. Nevertheless, the authors sustained that the research had limitations because, for example, there was no systematic assessment of responding during the absence of textual prompts (name of the item) and the 
fact that there was no data collection on generalization before intervention (Sarokoff, Taylor, \& Poulson, 2001).

The efficacy of training caregivers, mothers who were graduate students, on the implementation of script fading (recordings) with the purpose of improving conversation skills in three children with ASD from 3 to 6 years old in their residences was measured (Reagon \& Higbee, 2009). Three toy sets were selected: one of them was used for training with script fading and, the remaining, were assessed for generalization purposes. A multiple baseline design across different participants was employed to ensure experimental control. Each session lasted 5 min and the VD consisted in verbalizations based and not based on scripts.

In baseline, the mothers were asked to play with their children and, if the children verbalized, the mothers should answer them back. During training condition it was used a sound recorder; scripts were developed for toys and instructions with role-play for intervention with the children. The recorder played audios, which served as models about what the children could verbalize during playful activities (e.g. "Puzzles are fun"). After each child demonstrated fluency in repeating the recordings, four steps to fading them gradually were programmed so that the responding could occur free from their presence and the procedure was terminated when the scripts were totally removed. At last, follow up sessions were developed 2 weeks later (Reagon \& Higbee, 2009).

The results showed that the three children presented an increase on the verbalizations based on scripts and also other verbalizations not based on them, as well as there was generalization for the other two toy sets, which were not directly trained. It was noticed, nevertheless, a decline in verbalizations along intervention sessions and during the follow up, maybe due to an satiation effect to the toys, but it was also noticed an increase during the follow up with the introduction of new toys. The effects of script training and a new condition involving extinction were assessed on the development of variability in mand sentences for two children with ASD and aged 3 to 4 years (Betz, Higbee, Kelley, Sellers, \& Pollard, 2011). The authors discussed that script fading may produce gains in variability, considering that the literature demonstrates the development of spontaneous verbal responses and free from prompts. They also state that extinction produces variability as well and in a way that a given response topography should be reinforced only at the first time it was emitted. Script fading and extinction were combined to assess a possible variability effect in children's in situations in which they had the opportunity of demanding access to preferred edible items (Betz, Higbee, Kelley, Sellers, \& Pollard, 2011).

The children were able to emit at least one kind of mand sentence for preferred items. The used scripts were audible (recordings). For each child, scripts consisting in three mand sentences were employed (e.g. "I want + name of reinforcer"; "I need + name of reinforcer"). The design programmed to ensure experimental control was an $\mathrm{ABAB}$. Reinforcers were selected through tests of preference (to select the first three preferred edible reinforcers). In baseline, the experimenter reinforced all mand sentences emitted by the children who partici- 
pated. During extinction condition, each sentence was solely reinforced upon its first emission. During script training condition, each child learned to emit three mand sentences. Responses, based and not based on scripts, were reinforced with access to the most preferred snack. The children learned how to operate a button, which activated the recording and, when the children became more fluent in repeating the information, it was then faded in four steps. When the fading was over, a maintenance condition started; generalization probes under the presence of three or four new people and follow up sessions one or two weeks after the end of research were also conducted. The results showed that the extinction procedure, after script training and fading, was effective in increasing variability during the emission of mand sentences by two of the three children of the research and their performances were maintained in generalization probes and follow up probes (Betz, Higbee, Kelley, Sellers, \& Pollard, 2011).

The effects of script fading on the establishment of mands for missing items were assessed in another research with this purpose (Howlett, Sidener, Progar, \& Sidener, 2011). This could be the case of a child who does not find a toy in his/her house and, then, the child approaches an adult and says: "where is my little car?". The adult then says that the toy car is in the cabinet. Two boys diagnosed with ASD participated in the research. The manipulated scripts were audible (recordings). Data collection occurred in the students' classrooms. Experimental control by the independent variable (script fading) was measured through a multiple probe design across different participants.

The two children could respond in two kinds of trials. Those named "establishing operation trials (EO)" involved each child selecting a picture representing a preferred item among ten possibilities on a choice board where all pictures were attached. After choosing one picture and holding it, the child should then walk to a shelf with toys and grab a container with a picture, corresponding to the one previously selected by the child, attached. The container was empty and it would be expected that the child asked something like "where is my + name of the object". In other case related to what was known as abolishing operation (AO), the procedure was similar to the previous one, but the correct container contained the toy, which could be used from 2 to 3 minutes (Howlett, Sidener, Progar, \& Sidener, 2011).

During the baseline of the research for EO trials, in case that a mand was not emitted in $5 \mathrm{~s}$ after grabbing the container with the picture portraying a toy, differential consequences were not arranged and an instruction regarding a simple skill was presented as a redirection. Later, a new trial was initiated. During intervention, a recording representing the question "where is my + name of the toy?", was presented. This was done in case that the child, after selecting a picture portraying a given toy, walked next to a shelf where a container with the same picture was, grabbed it, opened it to see that it was empty, but did not say anything in $5 \mathrm{~s}$. The experimenter was about 1 meter away from the child. After a response was emitted, with or without help through the recording, the experimenter reported the place where the missing desired toy was (Howlett, Sidener, 
Progar, \& Sidener, 2011).

The recording (audible scripts) was faded in two steps. First, the children had to respond under the presence of the whole script. After two consecutive sessions in which they responded correctly until $5 \mathrm{~s}$ after the presentation of the recording, the ending criterion during the fading steps (first step as the word "where..."only; second step with the script/recording fully faded out) consisted in two consecutive sessions in which the children emitted the target response in the presence or absence of the recording. In AO trials, in which the desired item was located inside the container, if a question regarding the location of the reinforcer was made, which would not be appropriate, three more opportunities to respond by just playing with the item without questioning on the location were given. In case that did not work, the experimenter used a non-verbal model by keeping the lips closed, while looking at the child. As result, both children emitted more mands in EO trials and did not emitted mands during AO trials. One of them did not need the script fading procedure to demonstrate the target responses, but there was difficulty in discriminating the two kinds of trials initially. Maintenance of the established repertoire was demonstrated from 3 to 4 weeks later, after the end of the research and a generalization effect under the presence of new adults, items and environments was shown (Howlett, Sidener, Progar, \& Sidener, 2011).

The effects of script fading on the development of joint attention were assessed in children aged 4 to 7 years old with deficit in the mentioned skill, although they were able to communicate with other people, demonstrating the emission of full sentences. Joint attention corresponds to the sharing of attention between two social partners and an object or event. An example that illustrates this phenomenon could be the case of a child who shows a toy or another item of interest to an adult. The VD of the research consisted in the initiation of joint attention, with the demonstration of attention to a desired object, proper verbalization in the context and attention to the other person present, by turning the head and the body towards the other person's direction $2 \mathrm{~s}$ after verbalizations. These were defined as based or not based in scripts. A pre-training was programmed with the purpose to assess if the children could tact (say the name) of all stimuli and read all the sentences and phrases of the scripts and these skills were taught, if necessary. In the remaining conditions of the research, the design consisted in a multiple baseline across different participants. 30 bi-dimensional and tridimensional stimuli (toys) were selected and ten of them were specifically used to measure generalization. The stimuli were organized in several locations like the floor and a wall. An adult walked through a corridor, maintaining a distance of about 1 meter away from a child and the adult said: "let's go for a walk". The baseline lasted the time necessary for the children to be exposed to all stimuli. During intervention, scripts with phrases like "Look! It is a + name of the object" were used for all stimuli. Physical prompts were used for the children to pay attention to the stimuli, script and, later, to the adult (Pollard, Betz, \& Higbee, 2012). 
Script fading began by gradually removing the words until their complete absence. This was programmed after two consecutive sessions in which the full scripts were read from $90 \%$ to $100 \%$ correctly in one session. After this, the fading condition was implemented. When a child said something like: "Look! That is a car", the experimenter presented a description regarding function, characteristic or class to which the tacted stimulus belonged to: "Yes! And the car is red; yes! The car is pretty fast". The fading/training condition also involved multiple scripts to see if this variable would exert effect on independent verbalizations by the children. As this condition progressed and the participants became more independent, probes were conducted without scripts to assess if the children would emit new verbalizations (not directly based on the scripts used by the experimenter). In the end, a condition to measure generalization and maintenance was conducted with new stimuli and new partners in new environments to check if they would establish the occasion for the emission of joint attention responses and verbalizations. The results indicated that the children demonstrated joint attention and new verbalizations, including in the presence of new stimuli, partners and contexts and maintenance also was shown (Pollard, Betz, \& Higbee, 2012).

Script fading was used to teach children with ASD to initiate and maintain verbal interactions with multiple stimuli (toys) (Garcia-Albea, Reeve, Reeve, \& Brothers, 2014). Audible scripts (recordings) were used. The authors wanted to assess if the teaching would produce generalization of the verbal interactions with new toys. Four autistic boys aged 3 to 5 years old participated. The sessions were conducted in a classroom with bookcases with toys and a video camera on a tripod. Vehicles, instruments, balls, action figures, colored blocks and animals were the categories used in the research. Three toys pertaining to each category were used in the intervention and one more toy of each category was used in probes to measure generalization. Four other toys from a non-trained category were used in another test to also assess generalization. Three kinds of scripts were developed for each category of toys and the scripts were based in adaptations of verbalizations made by typical children from school in contexts in which they used to play and interact. Each script described the toy and emphasized a characteristic or function about it. A multiple probe design across different participants was used to ensure experimental control by the independent variable, the script fading. Like in the previous researches, the VD consisted in verbalizations initiated by the children and elaboration of responses when a communication partner was already involved in a conversation. The verbalizations should contain at least a name and a verb (Garcia-Albea, Reeve, Reeve, \& Brothers, 2014).

In all conditions, 13 toys were organized in three bookcases. There were three toys for each one of the three categories used in the study; one untrained toy of each one of the three trained categories to measure generalization; one toy of each category, which was not target of the training to measure generalization. Each bookcase contained one category of teaching, besides the stimulus from the untrained category with the purpose of measuring generalization and one was used at a time in each session. During a session, the child, communication part- 
ner and assistant were present in a classroom. The child was allowed to get any toy on the bookcase. After grabbing a toy, if the child verbalized, the partner responded and assisted him/her to operate a timer. The child had $30 \mathrm{~s}$ to play and, then, the partner left the room. In baseline, reinforcement, prompts and scripts were not used. The partner responded when the child initiated a verbal interaction. Each session lasted $10 \mathrm{~min}$. During the script fading condition, recorders were attached to the toys (Garcia-Albea, Reeve, Reeve, \& Brothers, 2014).

The communication partner and assistant provided prompts for the children to respond when necessary, by using the recorder and programming $30 \mathrm{~s}$ of access to the toy. After responding appropriately, the partner made a comment and waited a few seconds for the child to elaborate a response. Eight out of nine trials without errors was the criterion during the reading of the scripts and, then, the fading of scripts was programmed in six steps. A child had difficulty with the procedure and a methodological change was made (to keep the recorder out of reach) (Garcia-Albea, Reeve, Reeve, \& Brothers, 2014).

As result, the verbal interactions initiated by all children increased through script fading with multiple toys (verbalizations based or not based on scripts) and there was generalization to new toys. Nevertheless, the generalization did not happen in a new room and with a different communication partner. According to the authors, this could have been different if training in multiple contexts and with different people was conducted. Maintenance was verified for three out of four children (Garcia-Albea, Reeve, Reeve, \& Brothers, 2014).

More recent research was conducted on the effects of script fading in increasing communication among children with autism during playful group activities (Ledbetter-Cho, Lang, Davenport, Moore, Lee, Howell et al., 2015). The VD consisted in verbalizations based and not based on textual scripts. The participants were three autistic boys aged 4 to 6 years old. Sessions were conducted in the therapy room of a clinic from a University. Another space was also used to assess generalization. In baseline, the experimenter kept a toy set next to one of the children, who received verbal instructions to share the toys with the others. In case the child did not share, instruction was given one more time. After sharing the toys, the other children could play for $10 \mathrm{~s}$ and, then, an alarm was activated. The toys were removed and a new group was selected to replicate the procedure. Replications were conducted until three groups were used. In the intervention condition with textual scripts, two experimenters presented the scripts. Along the sessions, a group of toys was presented to one participant, as well as an instruction to share it. The script was presented $15 \mathrm{~cm}$ away from the eyes of the child, so the script could be read. When this happened, as well as the sharing of toys, the child was praised and $10 \mathrm{~s}$ of access to the toys were granted for the remaining children. The procedure was replicated with two more groups of toys (Ledbetter-Cho et al., 2015).

This work was later replicated with the other children, so they had the opportunity to learn about the scripts and share the toys. When the children became fluent in the process of reading the script, steps to fading them were pro- 
grammed until only a card without any words remained. In the end, the card also needed to be removed. After the complete removal of scripts in five sessions, probes to assess generalization were conducted with new toys, environments and children. Follow up sessions were also conducted 4 weeks after the end of intervention condition. The results of this research replicated those of the previous ones. The children rarely talked among them during baseline, but the intervention changed this reality, considering an increase of emission of verbalizations based and not based on scripts. The authors also suggested that the children eventually changed the topic of conversation during verbal exchanges among them and this was considered a more natural and dynamic process (Ledbetter-Cho et al., 2015).

Like in a previous research already described in this chapter on the effects of script fading in increasing the variability of building sentences to make requests (mands) (Betz, Higbee, Kelley, Sellers, \& Pollard, 2011), another study on the same theme was recently conducted in six children aged 3 to 5 years old (Sellers, Kelley, Higbee, \& Wolfe, 2016). Nevertheless, different from the previous research which programmed the training with three different mand sentences consecutively (one at a time), in the new one three sentences were taught simultaneously. Maintenance was also assessed. When variability was not demonstrated, an extinction condition was programmed to test its effects on mand variability. The sentences should contain noun, verb and the names of several preferred edible stimuli. During the first moment without extinction, a FR1 schedule of reinforcement was programmed to measure the effects on variability and maintenance. Textual scripts were programmed in these situations. Arbitrary criteria were defined for their fading. The FR1, after intervention with script fading, failed to demonstrate variability for three children. For the remaining ones, this variable was sufficient to produce variability. The authors discussed that, to cases in which an extinction condition is not necessary, it should be avoided anyway because extinction may produce a decrease in responding (Sellers, Kelley, Higbee, \& Wolfe, 2016).

Overall, all of the studies presented in this manuscript demonstrated the efficacy of script fading in establishing social repertoires in children with autism, with an emphasis in the process of initiating and maintaining verbal interactions with other people. The researchers also showed that script fading produced the elaboration of children's responses to other people's questions and comments and helped producing joint attention repertoires in children who lacked this skill; mands for information and the emission of mand sentences with variability. The methodology may be adapted to benefit children with different developmental levels. The scripts may be textual in cases in which deficits in communication are present, but the children present good reading performance. On the other hand, for children whose reading repertoire is compromised, audible scripts consisting in recordings may be used for the same purpose. Although the researches emphasize certain methodological limitations because the verbalizations may be limited to what is taught through scripts, several studies, whose 
most relevant information were discussed in this manuscript, demonstrated gains in generalization, as well as the repertoires taught through script fading were also maintained in follow up sessions several weeks after termination of intervention.

\subsection{The Current Research Report}

The following section of the manuscript concerns a research report on the effects of a script fading procedure on the establishment of communication skills in a 9 years old Brazilian child diagnosed with ASD. The goal was to see if the procedure could be effective for someone who belongs to another social context with differences in culture (Brazil) and if generalization of communication skills would occur with a new partner and in a new environment. Maintenance of possible acquired skills after intervention was also a target of the research.

\section{Method}

\subsection{Participant}

The participant of the research (referred here as CA) was 8 years old by the time that data collection was conducted. CA was able to build sentences to request access to several wanted items; he could state the names of hundreds of nonverbal stimuli, such as objects, pictures and actions, as well as he was able to identify them receptively upon hearing their names; he demonstrated generalized visual perception skills, matching pictures and objects to corresponding samples, identical or similar; he was also able to follow multiple verbal instructions; he could respond correctly in listener discrimination tasks related to the process of selecting objects and pictures upon hearing instructions describing function, feature and classes to which the stimuli pertain; CA also demonstrated verbal responses to several questions and could also list members pertaining to categories when demanded verbally to do so; the participant also showed academic skills, in the sense that he was able to read words, sentences and short paragraphs independently; he demonstrated some simple math skills and some spelling repertoire.

\subsection{Experimental Environment, Materials and General Teaching Procedure}

Sessions were conducted in a clinic situated in a private University. Assessments and interventions occurred in a room equipped with a table, chairs and materials like toys, videos and three sets of textual scripts consisting in three, four and five sentences, respectively, which CA had to learn through intervention to interact verbally with a communication partner. Initially, the experimenter presented a generic instruction to evoke the start of a communication episode. Immediately after this, textual scripts related to the topic of conversation were presented to CA. He had to read the scripts and, with time, a fading procedure was implemented in several steps until CA was able to verbalize the sentences without 
textual prompt. He had access to preferred toys and videos as reinforcers for cooperation during intervention. CA sat on one of the chairs and an experimenter sat on the other one next to CA. As an example of a set of textual scripts, one of them consisted in the following:

1) "Hey, (name of the experimenter), how are you?". After the child said this with or without the script, the experimenter said: "I am fine! And you?", and this established the occasion for the emission of a new response by CA (in this case, no script was used).

2) "Could you make tickles on my belly?". After the child said this with or without the script, the experimenter said: "Sure! Here we go!" and, then, started tickling the child.

3) "Let us play with the ball!". After saying this with or without the script, the experimenter mentioned: "Amazing! I love to play with you!" and, then, played with the child.

4) "Hey, (name of the experimenter), could you give me a hug?". After the child described this with or without the script, the experimenter said: "Sure! Here we go!" and, then, gave the child a hug.

5) "Would you dance with me?". After the child described this with or without the script, the experimenter said: "Yes! Let's do it!" and, then, started dancing with the child.

During intervention, the child had to develop fluency in reading all passages listed above. When this became true, a script fading condition began and each sentence was faded in seven steps. The first step, for example, consisted in removing the last word of each sentence. As an arbitrary criterion was achieved, the second step started and involved the removal of one more word and so on.

\subsection{Data Collection Procedures and Dependent Variable}

Sessions were conducted three times per week. The dependent variable was the number of sentences described with or without control by textual scripts. Each session involved several blocks of trials in which CA responded and each trial corresponded to a different sentence. Correct and incorrect responses were recorded on data sheets. A successful trial involved the recording of a + sign in a column corresponding to a block of trials. Incorrect responses (or no response) were recorded as - sign.

\subsection{Testing and Intervention Procedures}

\subsubsection{Baseline}

In this condition, the experimenter presented a general instruction for the child in order to assess if it would evoke a verbal interaction episode between him and the experimenter as a communication partner. As an example, an instruction regarding a topic of conversation, such as "let's talk about things you would like to do with me!", should be presented and CA had $30 \mathrm{~s}$ to start the verbal interaction. This condition was replicated across three different topics of conversation that were later addressed during intervention with script fading. Once it was 
proved that, in baseline condition, the child was not able to start and maintain a conversation with the experimenter on any of the topics mentioned, he would be directed to the intervention condition.

\subsubsection{Intervention}

As it was previously described in general procedure, the intervention consisted in two phases. The first one had the purpose of getting the child familiar with the scripts. He had to become able to read all of them fluently. The second phase aimed to fade out the textual scripts gradually in seven steps as an arbitrary criterion was met. In both phases, criterion was achieved in one block of trials without errors. The number of trials of each block varied depending on the set of scripts used. The first set contained five sentences; the second set, three sentences; and the third set, four sentences. It is also important to say that, during script fading training, data were taken on unscripted responses, which consisted in new verbalizations that the child could present contingent to comments that the experimenter made during the verbal interactions.

\subsubsection{Probes}

Two types of probes were conducted before and after the implementation of script fading training: probes in a new environment (the child's school) and probes with a new communication partner (another person besides the experimenter).

\subsubsection{Maintenance}

Maintenance of the established repertoires by the scripts was assessed two weeks after the script fading training was over.

\subsection{Experimental Design}

A concurrent multiple baseline design across different sets of textual scripts was used to ensure experimental control of script fading on the establishment of communication skills by CA, while interacting verbally with the experimenter. Experimental control by the independent variable (script fading) was demonstrated when changes in target repertoires (verbalizations free from script control) occurred for each set of textual scripts only when script fading was introduced (Cooper, Heron, \& Heward, 2006).

\subsection{Ethical Procedures}

An informed consent form was signed by the parents of the children, for their participation and the research was approved by an ethics committee in research with humans (authorization No. 1.189.331) humans from Ceuma University, São Luís-MA.

\section{Results}

Figure 1 presents the data of CA in all of the conditions of the research. 


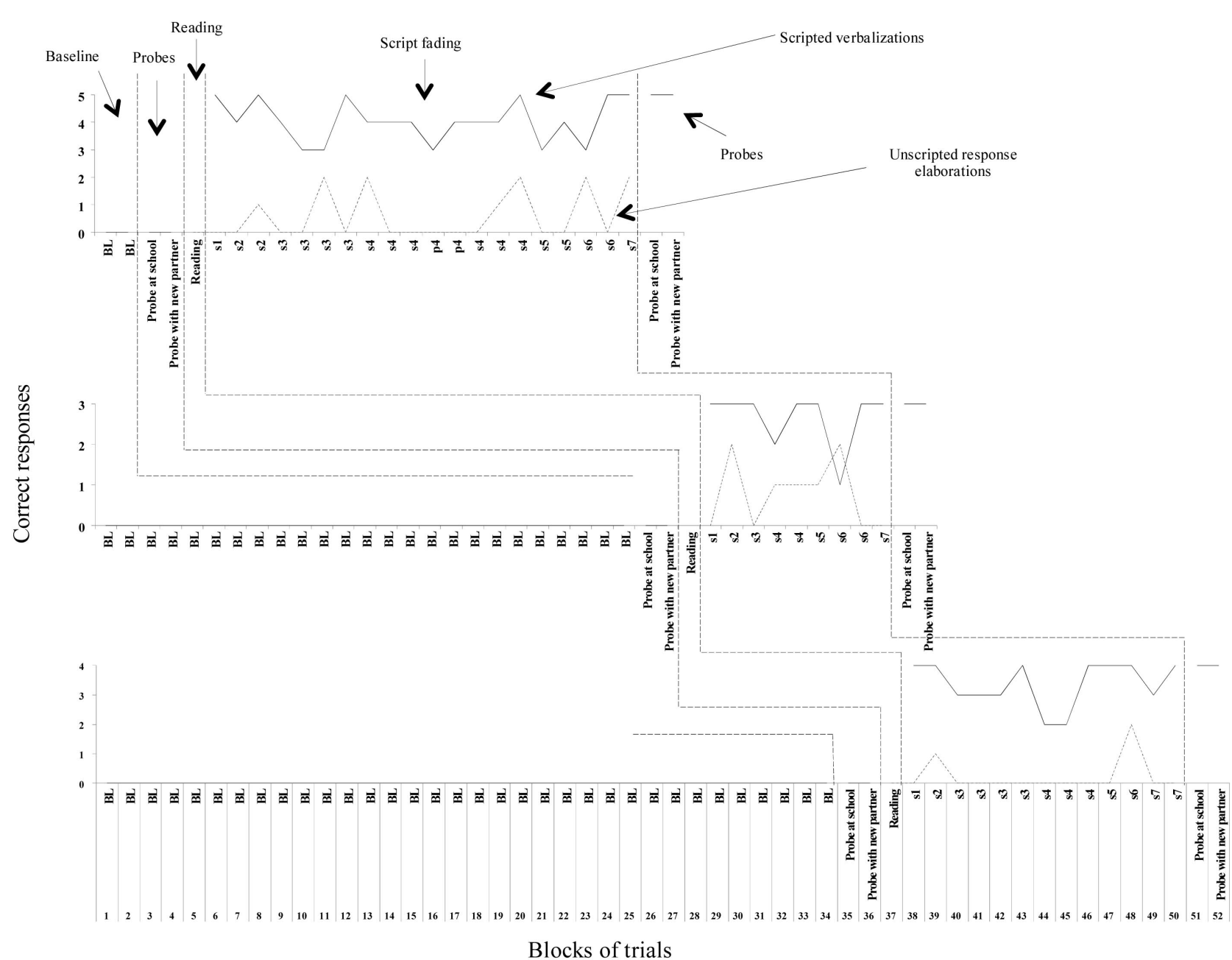

Figure 1. Number of correct scripted verbalizations and number of verbal response elaborations per block of trials, along several conditions for CA during the experiment. Data were collected in baseline (BL); probes at school (new environment) and with a new communication partner before and after intervention; reading condition (full textual scripts present); script fading training.

Each graph of Figure 1 represents data related to a different set of textual script used to improve communication skills. In baseline, CA was not able to verbally initiate and maintain conversation for all sets of scripts. Probes to assess these repertoires in a new environment and with a different communication partner also showed no repertoire regarding conversation before the implementation of any training. When scripts were added to a reading condition, CA was able to read all of the sentences of the textual scripts in a single block of trials solely. After script fading training started, 20 blocks of trials were necessary to set responding totally free from control of scripts for the first set; nine blocks were necessary for the same purpose for the second set of scripts; and 13 blocks of trials were needed for third set. Figure 1 also shows that, during script fading training for all sets, CA emitted some verbalizations contingent to comments by the experimenter, although they did not occur frequently. As an example, when the child asked the experimenter to dance with him with or without control by the script and the experimenter made a comment contingent to it, sometimes 
CA said something like "I am dancing with you". These kind of verbalizations were considered unscripted, since they were not directly related to the scripts used to expand the participant's communication skills. The experimenter also praised the child for making comments during verbal interactions.

Script fading training condition successfully established the verbalizations totally free from script control for all sets, as the fading of textual stimuli gradually progressed. Experimental control by the independent variable was demonstrated across all sets of textual scripts because changes in verbal repertoires were seen only after training for each set. After termination of training, new probes at school and with a new communication partner showed full generalization of verbalizations developed during script fading training. In the end, maintenance of established performance occurred two weeks after script training was finished.

\section{Discussion}

Data from the current research replicated those from previous scientific literature regarding the effects of script fading training on the establishment of communication skills in children with ASD (Krantz \& McClannahan, 1993; Krantz, \& McClannahan, 1998; Sarokoff, Taylor, \& Poulson, 2001; Reagon \& Higbee, 2009; Betz, Higbee, Kelley, Sellers, \& Pollard, 2011; Howlett, Sidener, Progar, \& Sidener, 2011; Pollard, Betz, \& Higbee, 2012; Garcia-Albea, Reeve, Reeve, \& Brothers, 2014; Ledbetter-Cho et al., 2015; Sellers, Kelley, Higbee, \& Wolfe, 2016). Script fading was effective in improving communication skills of an 8-year-old child with ASD across different partners and environments. Besides, there was some evidence of emission of new verbal responses not based on scripts. A maintenance condition was implemented and the child showed the established repertoires two weeks after training was finished. The current research extended those from the previous literature, but some comments were worthy to mention. The current study was conducted in Brazil, where evidence based methodologies, such as those from Applied Behavior Analysis, were not so present in schools when compared to the reality of some schools in United States. Apparently, in the city where the research occurred, only a minority of autistic children benefited from evidence based practices at school. The participant showed important generalization data in a new environment, which was precisely his own school and, in this sense, it was believed that the script fading procedure and others should be replicated in a systematic fashion in order to promote a better functioning of CA in an important social context such as school. This study was also concerned with the establishment of school inclusion practices (Mitijáns-Martínez, 2005; Galvão \& Beckman, 2016). Although the results of the study were positive, the fact that it involved a single participant might be seen as a limitation. It is relevant that the procedure of the current research be replicated across new participants, unfamiliar with the script fading procedure, and generalization to new settings and communication partners and maintenance should be assessed as well. 
It is important to mention that several of the studies on script fading were conducted at the participants' schools. The establishment of procedures to improve communication skills in children with ASD seems to be very relevant for social and academic achievement and an educational context, such as school, is a place where social skills should be considered pre-requisites for development.

In Brazil, the insertion of people with specific special needs at regular schools represented a recent story, which became a reality due to the expansion of educational policies for inclusion. In special, the National Policy of Special Education on the Perspective of Inclusive Education (Brazil, 2008) and the Law 12.764, known as Berenice Piana Law (Brazil, 2012) were implemented. School and Educational Psychology, as an area of research and intervention, sustains that the role of school is to promote improvements in psychological processes of the learners. This goal should warrant the development of competencies, which favors life in society with autonomy. In Brazil, School Psychology understands that the history of recent changes in policies produces challenges to the establishment of pedagogical goals by the Pedagogical Policy Project and, for this, it is important that school psychologists help with the implementation of pedagogical practices, which favor inclusion (Mitijáns-Martínez, 2005; Galvão \& Beckman, 2016).

\section{Conflicts of Interest}

The authors declare no conflicts of interest regarding the publication of this paper.

\section{References}

Allen, K. D., \& Cowan, R. J. (2008). Naturalistic Teaching Procedures. In J. K. Luiselll, D. C. Russo, W. P. Christian, \& S. M. Wilczynski (Eds.), Effective Practices for Children with Autism: Educational and Behavior Support Interventions That Work (pp. 240-270). New York: Oxford University Press. https://doi.org/10.1093/med:psych/9780195317046.003.0011

Alwell, M., Hunt, P., Goetz, L., \& Sailor, W. (1989). Teaching Generalized Communicative Behaviors within Interrupted Behavior Chain Contexts. Journal of the Association for Persons with Severe Handicaps, 14, 91-100. https://doi.org/10.1177/154079698901400201

American Psychiatry Association (APA) (2013). Diagnostic and Statistical Manual of Mental Disorders (5th ed.). Washington DC: American Psychiatric Association. https://doi.org/10.1176/appi.books.9780890425596

Betz, A. M., Higbee, T. S., Kelley, K. N., Sellers, T. P., \& Pollard, J. S. (2011). Increasing Response Variability of Mand Frames with Script Training and Extinction. Journal of Applied Behavior Analysis, 44, 357-362. https://doi.org/10.1901/jaba.2011.44-357

Brazil (2008). Política Nacional de Educação Especial na Perspectiva da Educação Inclusiva [The National Policy of Special Education on the Perspective of Inclusive Education]. Brasília: MEC/SEESP.

Brazil (2012). Política Nacional de Proteção dos Direitos das Pessoas com Transtorno do Espectro do Autismo [National Policy on the Protection of the Rights of Persons with Autism Spectrum Disorder]. Brasília: MEC/SEESP. 
Carr, J. E., LeBlanc, L. A., Rosati, T. C., \& Conroy, S. A. (2012). The Effects of the Question "What Is This?" on Tact-Training Outcomes of Children with Autism. Journal of Applied Behavior Analysis, 45, 539-547. https://doi.org/10.1901/jaba.2012.45-539

Cooper, J. O., Heron, T. E., \& Heward, W. L. (2006). Applied Behavior Analysis. London: Pearson Education.

Galvão, P. G., \& Beckman, M. V. R. (2016). An Educação Inclusiva no Contexto da Política Nacional da Educação Especial: Atuação e Compromisso da Psicologia Escolar [Inclusive Education in the Context of the National Policy of Special Education: Performance and Commitment of School Psychology]. In D. C. Matos (Ed.), Análise do Comportamento Aplicada ao Desenvolvimento Atípico con Ênfase em Autismo (pp. 199-226). Porto Velho: AICSA.

Garcia-Albea, E., Reeve, S. A., Reeve, K. F., \& Brothers, K. J. (2014). Using Audio Script Fading and Multiple-Exemplar Training to Increase Vocal Interactions in Children with Autism. Journal of Applied Behavior Analysis, 47, 325-343.

https://doi.org/10.1002/jaba.125

Greer, R. D., \& Ross, D. E. (2008). Verbal Behavior Analysis: Inducing and Expanding Complex Communication in Children with Severe Language Delays. Boston, MA: Allyn \& Bacon.

Halle, J. W., Marshall, A. M., \& Spradlin, J. (1979). Time Delay: A Technique to Increase Language Use and Facilitate Generalization in Retarded Children. Journal of Applied Behavior Analysis, 1, 109-120. https://doi.org/10.1901/jaba.1979.12-431

Howlett, M. A., Sidener, T. M., Progar, P. R., \& Sidener, D. W. (2011). Manipulation of Motivating Operations and Use of a Script-Fading Procedure to Teach Mands for Location to Children with Language Delays. Journal of Applied Behavior Analysis, 44, 943-947. https://doi.org/10.1901/jaba.2011.44-943

Krantz, P. J., \& McClannahan, L. E. (1993). Teaching Children with Autism to Initiate to Peers: Effects of a Script-Fading Procedure. Journal of Applied Behavior Analysis, 26, 121-132. https://doi.org/10.1901/jaba.1993.26-121

Krantz, P. J., \& McClannahan, L. E. (1998). Social Interaction Skills for Children with Autism: A Script-Fading Procedure for Beginning Readers. Journal of Applied Behavior Analysis, 31, 191-202. https://doi.org/10.1901/jaba.1998.31-191

Ledbetter-Cho, K., Lang, R., Davenport, K., Moore, M., Lee, A., Howell, A., Drew, C., Dawson, D., Charlop, M. H., Falcomata, T., \& O’Reilly, M. (2015). Effects of Script Training on the Peer-to-Peer Communication of Children with Autism Spectrum Disorder. Journal of Applied Behavior Analysis, 48, 785-799.

https://doi.org/10.1002/jaba.240

Matos, D. C. (Ed.) (2016). Análise do comportamento aplicada ao desenvolvimento atípico com ênfase em autism (1st ed.) [Applied Behavior Analysis to Atypical Development with an Emphasis on Autism]. Porto Velho: AICSA.

Mitijáns-Martínez, A. (2005). Inclusão Escolar: Desafios para o psicólogo [School Inclusion: Challenges for the Psychologist]. In A. Mitijáns-Martínez (Ed.), Psicologia escolar e compromisso social: Novos discursos, novas práticas (pp. 95-114). Campinas: Alínea.

Pérez-González, L. A., Pastor, A., \& Carnerero, J. J. (2014). Observing Tacting Increases Uninstructed Tacts in Children with Autism. The Analysis of Verbal Behavior, 30, 62-68. https://doi.org/10.1007/s40616-013-0003-6

Pollard, J. S., Betz, A. M., \& Higbee, T. S. (2012). Script Fading to Promote Unscripted Bids for Joint Attention in Children with Autism. Journal of Applied Behavior Analysis, 45, 387-393. https://doi.org/10.1901/jaba.2012.45-387

Reagon, K. A., \& Higbee, T. S. (2009). Parent-Implemented Script Fading to Promote 
Play-Based Verbal Initiations in Children with Autism. Journal of Applied Behavior Analysis, 42, 659-664. https://doi.org/10.1901/jaba.2009.42-659

Richman, S. (2001). Raising a Child with Autism: A Guide to Applied Behavior Analysis for Parents. London and Philadelphia: Jessica Kingsley Publishers.

Rogers-Warren, A., \& Warren, S. (1980). Facilitating the Display of Newly Trained Language in Children. Behavior Modification, 4, 361-382. https://doi.org/10.1177/014544558043006

Sarokoff, R. A., Taylor, B. A., \& Poulson, C. L. (2001). Teaching Children with Autism to Engage in Conversational Exchanges: Script Fading with Embedded Textual Stimuli. Journal of Applied Behavior Analysis, 34, 81-84. https://doi.org/10.1901/jaba.2001.34-81

Sellers, T. P., Kelley, K., Higbee, T. S., \& Wolfe, K. (2016). Effects of Simultaneous Script Training on the Use of Varied Mand Frames by Preschoolers with Autism. The Analysis of Verbal Behavior, 32, 15-26. https://doi.org/10.1007/s40616-015-0049-8

Skinner, B. F. (1978). O Comportamento Verbal [Verbal Behavior]. São Paulo: Cultrix. (Publicação Original, 1957)

Skinner, B. F. (2003). Ciência e Comportamento Humano [Science and Human Behavior]. Tradução organizada por J. C. Todorov, \& R. Azzi. São Paulo: Edart. (Trabalho original publicado em 1953)

Sundberg, M. L., \& Partington, J. W. (1998). Teaching Language to Children with Autism or Other Developmental Disabilities. Danville, CA: Behavior Analysts, Inc.

Williams, G., Carnerero, J. J., \& Pérez-González, L. A. (2006). Generalization of Tacting Actions in Children with Autism. Journal of Applied Behavior Analysis, 39, 233-237. https://doi.org/10.1901/jaba.2006.175-04 